\title{
A TREE-BASED APPROACH TO ESTIMATE WOOD VOLUME FROM LIDAR DATA: A CASE STUDY IN A PINE PLANTATION
}

\author{
Ahmed Hamrouni ${ }^{1}$, Cédric Véga ${ }^{2}$, Jean-Pierre Renaud ${ }^{3}$, Sylvie Durrieu ${ }^{4}$, Marc Bouvier ${ }^{4}$ \\ 1: Institut Français de Pondichéry, Pondichéry, Inde, hamrouni.ahmed@ifpindia.org \\ 2: IGN, LIF, 11 rue lle de Corse, 5400 Nancy, cedric.vega@ign.fr \\ 3 : ONF, 11 rue lle de Corse, 5400 Nancy, jean-pierre.renaud-02@onf.fr \\ 4: UMR TETIS Irstea-Cirad-AgroParisTech/ENGREF, Maison de la Télédétection en Languedoc-Roussillon, \\ 500, rue J.F. Breton BP 5095, 34196 Montpellier Cedex 05, France, sylvie.durrieu@teledetection.fr, \\ marc.bouvier@teledetection.fr
}

\begin{abstract}
Résumé
Nous proposons une méthode pour estimer le volume d'arbres individuels d'une zone dominée par des pins maritimes, à partir de données LiDAR aéroporté. Le nuage de point à été segmenté à partir de l'algorithme PTrees. Pour chaque arbre segmenté, la hauteur du plus haut point, le volume de l'enveloppe du nuage et de l'enveloppe de la couronne ont été utilisés dans des modèles non linéaires pour prédire le volume total d'arbres mesurés sur le terrain. A l'arbre, les modèles testés permettent d'estimer le volume avec une erreur quadratique moyenne (RMSE) de l'ordre de $35 \%$. Ce niveau d'erreur a plusieurs origines. Tout d'abord les volumes terrain ont été estimés à partir de tarifs de cubage qui décrivent un arbre moyen. Ainsi une variabilité autour de cet arbre moyen peut être induite par des variations de fertilité ou de sylviculture qui agissent localement sur la croissance des arbres. Le passage à la placette permet de diminuer la RMSE d'un facteur 2, autour de 15\%. Ce changement d'échelle permet en effet de compenser les erreurs liées à la segmentation et qui se traduisent par des fausses détections d'arbres soit omissions qui génèrent des fusions de couronnes. Par ailleurs, nos résultats suggèrent que des paramètres de hauts niveaux, tel que la hauteur de la base du houppier, ou le volume de la couronne peuvent introduire du bruit dans les modèles. Nous recommandons donc de sélectionner les variables LiDAR afin de limiter la propagation d'erreur, tout en ajoutant des variables permettant de décrire l'environnement de l'arbre afin de mieux prendre en compte ses conditions de croissance.
\end{abstract}

Mots-clés : LiDAR, Télémétrie laser aéroportée, segmentation d'arbre, changement d'échelle, allométrie

\begin{abstract}
We developed an-object based framework to assess individual tree volume from airborne LiDAR data in a pinedominated forest. Individual tree crowns were extracted using a point-based segmentation algorithm and total tree volume was estimated using height and either tree or crown bounding volume information using nonlinear models. Treelevel models provided root mean squared errors (RMSE) around 30\%. Scaling volume at the plot level allows to reduce RMSE by a factor 2, i.e. around $15 \%$. This scale change may benefits from error compensation associated to segmentation involving false tree detections or tree omissions leading to crown fusions. Along with height, crown volume was found to be a good predictor of tree volume, but suffers from computational issues that may further induce variability in the models. Future work should integrate an analysis of tree neighborhood in order to improve tree- models by the use of indices reflecting competition and growth conditions.
\end{abstract}

Keywords: LiDAR, Airborne laser scanning, tree segmentation, scaling, allometry

\section{Introduction}

Light Detection and Ranging, or LiDAR, is a state of the art active remote sensing technology providing detailed $3 \mathrm{D}$ information of the Earth's surface. Ranging systems compute distance measurements based on the timelapse between the emission and the reception of a laser signal sent toward the ground. The precise positioning of ground targets having interacted with the signal is computed by integrating sensor position and orientation measured by an onboard global positioning system (GPS) and an inertial measurement unit (IMU), respectively [Baltsavias, 1999].
Owing to the capacity of laser signals to partially penetrate forest canopies, LiDAR has emerged as one of the most promising remote sensing technology for characterizing and monitoring forest structure and function over large areas and for supporting forest management, mapping and planning [Wulder et al., 2012; Næsset et al., 2011; van Aardt et al., 2008]. Using high sampling densities (i.e. at least 4 pulses per square meter) [Evans et al., 2009], forest trees can even be characterized individually, enhancing labourintensive field-based inventories [Avery and Burkhart, 2001] and supplying information needed for forest models. Such object-oriented approaches are still under 
development but operational applications become feasible owing to the continuous improvement of both LiDAR technologies and processing methods [Leckie et al., 2005].

Various methods have been developed for extracting and characterizing individual tree from LiDAR data. Most approaches rely on the analysis of a 2D canopy height model $(\mathrm{CHM})$ describing the height structure of the outer canopy layer [Bongers, 2001]. These methods mostly consist in identifying tree apices, through the detection of local maxima (LM), and further constructing crown segments using geometrical properties of the CHM [Solberg et al.,2006; Popescu et al., 2002].

However these approaches suffer from some limitations. The point to raster transformation causes information loss and optimization of LM detection remains difficult. To overcome these issues, various methods have been proposed. Reitberger et al. (2009) combined a CHM watershed segmentation algorithm with a point clustering algorithm to refine watershed segments and detect dominated trees. Morsdorft at al. (2004) used a voxel-based approach with a k-means clustering algorithm to retrieve individual trees. But the LM detection remained based on a CHM. Wang et al. (2008) combined loaded the point cloud into a voxel structure and used a hierarchical morphological algorithm to generate crown region at different height intervals. A merging algorithm was then applied to the different layers to reconstruct trees. Methods to directly process point clouds have also been proposed. Ferraz et al. (2012) introduced a clustering approach based on a mean-shift algorithm only requiring a scale parameter, which has to be optimized per vegetation layers defined independently. Li et al. (2012) developed a distance based algorithm to sequentially segment trees, from the highest to the smallest. The problem of accurate identification of LM was solved by using global maxima (GM), defined in each segmentation sequence as the highest unclassified point. Vega et al. (2014) introduced a hierarchical, multi-scale and multi-criteria algorithm. The algorithm is also built on the concept of GM, but all the trees are extracted simultaneously. Moreover the algorithm tackles the problem of point cloud distortion in slope areas by extracting trees using elevation ( $Z$ ) instead of height ( $\mathrm{H}=\mathrm{Z}-\mathrm{DTM})$ as usually done.

Crown segmentation results can be directly used to assess forest parameters such as tree density, tree height distribution, and cover rate. In addition, many approaches have been proposed to use segmentation results to assess higher-level tree parameters such as volume or biomass. Methods performed either at plot [Popescu et al. 2004; Bortolot and Wynne 2005] or tree level [Allouis et al. 2013, Person et al. 2002, Hyyppä et al. 2001]. However, most of these methods relied on CHM-based segmentation products and relied on height information alone [Bortolot and Winne 2005], sometimes in combination with crown area [Popescu et al. 2004, Person et al. 2002, Hyyppä et al. 2001]. Chen et al. (2007) demonstrated that volume under the CHM performed better than height and crown area to predict stem basal area and volume. Allouis et al. (2013) further reported that the crown bounding volume, computed from crown height and diameter was a good predictor of both wood volume and above ground biomass and that using vegetation profile information improved the accuracy of biomass predictions.

Based on the aforementioned work, this paper proposes an object-oriented approach to estimate wood volume at plot level from individual tree measurements. Tree segmentation is conducted using PTrees [Vega et al. 2014] and sub-point-clouds associated with each tree crown are further analyzed to compute crown structural parameters and developed a LiDAR-based, tree-level predictive model of wood volume. Model accuracy is assessed at both tree and plot levels to study how segmentation errors and accuracy of tree volume estimations behave when information is aggregated at plot level for smaller scale mapping.

\section{Study area and data}

\subsection{Study area}

The study area is part of the Landes de Gascogne lowland area in South-Western France $(44.40 \mathrm{~N}$, $0.50 \mathrm{~W}$ ), and spreads over $60 \mathrm{~km}^{2}$ of forests dominated by even-aged and monospecific stands of maritime pine (Pinus pinaster Aiton).

\subsection{Field data}

A total of $30,15 \mathrm{~m}$ radius plots were surveyed during April-June 2011. Within each plot, all trees having a circumference at breast height $(\mathrm{C}, 1.3 \mathrm{~m})$ greater than $23.5 \mathrm{~cm}$, were mapped using angle and distance measurements from the plot centre. For each countable tree, species, status (i.e. dominant, co-dominant, dominated), and height $(\mathrm{H})$ were collected. Height, distance and angle were assessed using a clinometer (Haglöf, Sueden). Each plot centre was geolocated with a sub-decimeter accuracy using a differential GPS (Leica GPS 120, Switzerland) and a total station (Leica TS02, Switzerland).

A total of 709 trees were measured on the field (Table 1), $94.35 \%$ of which were maritime pine ( $n=669$ ), sometimes mixed with a few pubescent oaks (Quercus Pubescens Willd.) $(\mathrm{n}=40)$. Total aboveground wood volume (TV) was derived from species-specific allometric equations based on height $(H)$ and circumference at breast height $(C)$ and developed in the framework of the EMERGE project (Deleuze et al., 2013):

$T V=S H *\left(H * C^{\wedge} 2 /\left(4 * \pi *(1-1.3 / H)^{\wedge} 2\right)\right.$

where $\mathrm{SH}$ is a shape factor computed using equation (2) :

$S H=a+b * \sqrt{C} / H+d * H / C$ 
where $a, b$ and $d$ are species-specific parameters.

Along with individual tree volumes, plot volumes (PV) were computed by summing the individual volumes of all the countable trees of the plot. Field data characteristics are summarized Table 1.

\begin{tabular}{|l|l|l|}
\hline Volume $\left(\mathrm{m}^{3}\right)$ & $\begin{array}{l}\text { Trees } \\
(\mathrm{n}=709)\end{array}$ & $\begin{array}{l}\text { Plots } \\
(\mathrm{N}=30)\end{array}$ \\
\hline Minimum & 0.02 & 5.59 \\
\hline Mean & 0.85 & 20.2 \\
\hline Max & 4.27 & 44.03 \\
\hline Standard deviation & 0.82 & 7.81 \\
\hline
\end{tabular}

Table 1: Summary of the field measured volume $\left(\mathrm{m}^{3}\right)$ at tree and plot levels.

\subsection{LiDAR data}

LiDAR data were acquired during April 2011 by Sintegra (France) using a Riegl LMS-Q560 fullwaveform system (Riegl, Austria). This small footprint fullwaveform airborne system was operated at $550 \mathrm{~m}$ above the ground level using a $29.5^{\circ}$ maximum scan angle and a $10 \mathrm{kHz}$ pulse frequency of $10 \mathrm{kHz}$, leading to a pulse density of 8 pulses.m ${ }^{-2}$. A $40 \%$ overlap was set between adjacent flight lines to increase point density and avoid slivers. At the aforementioned flight altitude, the $0.5 \mathrm{mrad}$ beam divergence produced a $27.5 \mathrm{~cm}$ footprint at the ground level.

\section{Methods}

\subsection{LiDAR preprocessing}

Waveform processing and ground point classification were performed by the data provider. Waveform processing was performed using RiAnalyze software (Riegl, Austria), and led to an average density of first returns of 10 pts. $\mathrm{m}^{-2}$. Ground point classification was performed using the TIN-iterative algorithm (Axelsson, 2000) implemented within Terrascan (Terrasolid, Finland). The resulting triangulated irregular network (TIN) was then converted into a $1 \mathrm{~m}$ digital terrain model (DTM).

\subsection{Tree extraction}

Individual tree extraction was performed for each plot using PTrees algorithm [Vega et al. 2014]. PTrees is a hierarchical, multi-scale and multi-criteria segmentation algorithm extracting tree segments from untransformed elevation data $(Z)$. The $Z$ to Height $(H)$ conversion is achieved at the tree crown level following a two stage procedure. First, tree apex height $\left(\mathrm{H}_{\text {apex }}\right)$ is computed by subtracting to the elevation of the highest point of the crown the DTM value corresponding to the planimetric position of this apex $\left(H_{\text {apex }}=Z_{\max }-D T M\right)$. Then, the height of each point $\left(\mathrm{H}_{\mathrm{Pt}}\right)$ associated to the tree crown is computed with reference to $\mathrm{H}_{\mathrm{apex}}\left(\mathrm{H}_{\mathrm{Pt}}=\mathrm{H}_{\mathrm{apex}}-\left(\mathrm{Z}_{\max }-\right.\right.$ $\left.Z_{P t}\right)$.
The performance of PTrees over 10 plots of the study area was reported in Vega et al. (2014). The algorithm enabled to detect $93 \%$ of the trees, among which $94 \%$ of the dominant trees and $50 \%$ of the dominated ones. False detections were limited to $2.3 \%$. An example of a segmented plot is provided in Figure 1.

For the purpose of that study, a $10 \mathrm{~m}$ buffer was used around each plot to ensure good crown segmentation for all the trees with the trunk located within the plot. But only the segmented crowns having their highest point within the field plot radius were kept for further analyses. Because field measurements were limited to trees having a circumference greater than $23.5 \mathrm{~cm}$ we used a $\mathrm{C}-\mathrm{H}$ relationship developed locally ( (3), R2 = 0,83 , Mean Relative Error $=18 \%, N=549$ ) to identify and discard tree segments with a $\mathrm{C}$ predicted from their total height below $23.5 \mathrm{~cm}$.

$C=-8.36+5.25 * H$

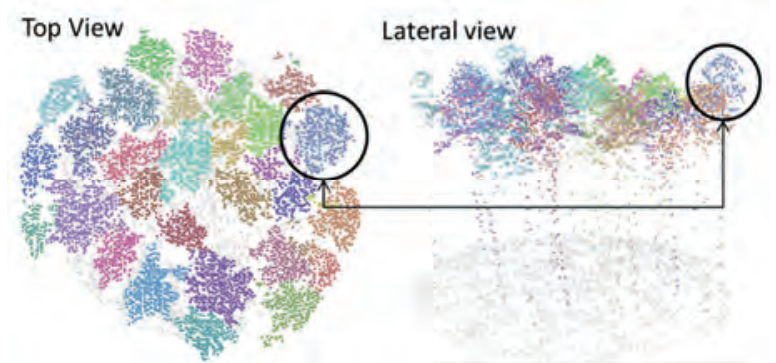

Figure 1 : Segmentation results over a $15 \mathrm{~m}$ radius circular plot having a tree density of 206 stems ha-1.

\subsection{Tree-level LiDAR metrics}

The segmented point cloud was used to derive tree parameters. Along with total tree height $\left(\mathrm{H}_{\text {apex }}\right)$, we computed the Convex Hull $(\mathrm{CH})$ of the sub-point cloud associated with each tree and projected on the $(\mathrm{X}, \mathrm{Y})$ plane. $\mathrm{CH}$ is the convex envelop of the projected segment and is defined by a list of summits. It can be used as a proxy of the limit of the projected area $\left(\mathrm{C}_{\mathrm{PA}}\right)$ of the crown at the ground level. The product $\mathrm{H}_{\mathrm{apex}}{ }^{*} \mathrm{C}_{\mathrm{PA}}$ was used to compute the tree Bounding Volume $\left(\mathrm{T}_{\mathrm{BV}}\right)$ defined as the volume including the whole tree segment.

Because crown dimensions were found to be related to tree volume [Avery and Brukhart, 1994], we also used the segmented point cloud to estimate the crown base height $\left(\mathrm{H}_{\mathrm{CB}}\right)$ [Popescu and Zhao, 2008], and compute the crown bounding volume $\left(\mathrm{C}_{\mathrm{BV}}\right)$ defined of the part of $\mathrm{T}_{\mathrm{BV}}$ between $\mathrm{H}_{\mathrm{apex}}$ and $\mathrm{C}_{\mathrm{BV}}$. $\mathrm{H}_{\mathrm{CB}}$ was computed using a four step procedure adapted from the method proposed by [Holmgren and Persson, 2004]. First, a tree-height histogram was generated by binning the point cloud into $1 \mathrm{~m}$ height intervals and summing the number of points in each bin. Then a mask of 0 and 1 digits was computed. For each height bin, the mask value was set to 0 if the amount of points was lower than $2 \%$ of the 
total number of aboveground points and set to 1 otherwise. Each value of 1 surrounded by two 0 was further switched to 0 . Finally, the crown base was estimated as the height of the first bin above the ground greater than 0 .

\subsection{Development of aboveground volume models and validation at tree and plot levels}

Two predictive models of TV were developed: a model using $\mathrm{H}_{\text {apex }}$ and $\mathrm{T}_{\mathrm{BV}}$ (Model 1), and an enhance model using $C_{B V}$ instead of $T_{B V}$ (Model 2). While $C_{B V}$ required additional computation to be estimated, we hypothesized that $\mathrm{C}_{\mathrm{BV}}$ would be a better predictor of tree volume, providing more accurate information about tree structure.

The models were developed under non-linear least squares framework using the gn/s function of the nlme package in $\mathrm{R}$ (cran.r-project.org/). The power variance function was used to model heteroscedasticity using height $\left(\mathrm{H}_{\text {apex }}\right)$ as a weighting variable. The accuracy of the predictive models was assessed by performing a leave-one-out cross-validation (LOOCV) [Picard and Cook 1984], and reporting root mean squared error (cVRMSE), relative RMSE (cv-RMSE) and adjusted determination coefficient (cv-adj. $R^{2}$ ).

Along with the tree level assessment, we evaluated the plot-level volume by summing individual tree predictions. The resulting volumes were compared to their field counterparts, through the computation of the mean relative error and the relative RMSE.

\section{Results and Discussion}

For the 30 plots considered, 748 segmented trees were finally selected. This number represents $105.5 \%$, of field measured trees, and includes both tree omissions and false detections. This is in accordance with Vega et al. (2014) who reported slight over-segmentation issues above the same area.

For the sake of tree-level development, only 10 plots including a total of 161 segmented trees were used. Each tree segment was manually matched with the field data for model development. Such a manual process allows to control the quality of the dataset, avoiding wrong assignment of trees that might occur when automatic matching algorithms are used. Tree-level results are provided in Table 2 and Figure 2. Overall, the model including height $\left(\mathrm{H}_{\mathrm{apex}}\right)$ and crown volume $\left(\mathrm{C}_{\mathrm{BV}}\right.$ ) (Model 2) performed slightly better than the one based on height and tree bounding volume $\left(\mathrm{T}_{\mathrm{BV}}\right)$ (Model 1). While both models showed similar adjustments (i.e. similar cv-adj. $\mathrm{R}^{2}$ ), root mean squared error (cv-RMSE) was lower by $1.16 \%$ when using Model 2 , with a value of $34.68 \%$. This result was expected because $C_{B V}$ should provide more precise information about tree crown structure than $\mathrm{T}_{\mathrm{BV}}$. However, the cv-RMSEs of both models remain high. This might be explained by various reasons. Field volumes were derived from $\mathrm{C}$ and $\mathrm{H}$ using a model describing the relationship between the volume and the tree size all over the life of an average tree. However, growth allocation to $\mathrm{H}$ and $\mathrm{C}$ is nonlinear and is function of site productivity and silviculture. At a given time, the relationship between these parameters may not reflect equilibrium, showing departure from the average tree. Hence volume estimations are not robust to local growth conditions (ie. competition, life history), which might contribute to inflation in RMSE. Furthermore, Antin et al. (2013) emphasized that crown allometries are more robust to local growth conditions than stem ones for predicting volume. This different dynamics between field measured and LiDAR derived parameters may lead to discrepancies when comparing LiDAR derived volume to field reference one. In addition, as LiDAR-based models for volume prediction will always be affected by errors in field volume prediction models, their improvement requires the use of real volume measurements in the field, obtained either from destructive tree sampling or from new non-destructive means like those offered by terrestrial LiDAR. Improved models might also be achieved by integrating parameters describing the local environment of the tree, such as the distance and size characteristics of the $\mathrm{K}$ nearest trees in order to catch individual-tree plasticity as well as the competition level resulting from local growing conditions.

These issues were partially overcome at the plot level (Table 3). For both models, plot RMSEs decreased by a factor 2 , from above $30 \%$ to $16.19 \%$ for Model 1 and $17.87 \%$ for Model 2. This gain might be explained by a tree compensation effect at the plot level. In Scots pine stands, Peuhkurinen et al. (2011) reported an underestimation of stem number and an overestimation of mean stem size compensating each other in the estimates of timber volume at the plot level. Here, we observed an opposite effect, with an overestimation of the stem number which might be compensated by an underestimation of crown dimensions. However, a better understanding of the effect of both tree omission and false detection at the plot level would require a detailed analysis of the effect of segmentation quality in a range a plot densities, as well as a comparison of the properties of false crown with respect to true ones in similar growing environments. But the information was not available in the framework of the study.

Interestingly, Model 1 performed better than Model 2 at the plot level. Owing to the performance obtained at the tree level, such a result cannot be related to the reported inaccuracies in crown based height estimation [Korhonen et al., 2013]. For example, Jung et al. (2011) indicated that LiDAR-derived $\mathrm{H}_{\mathrm{CB}}$ is generally overestimated, because of both signal attenuation and crown overlapping. Here, the relative inter-crown distance as well as the important crown porosity of maritime pine should limit crown overlapping and 
guarantee a good sampling of the whole tree structure. Again, the driven source of error in $\mathrm{H}_{\mathrm{CB}}$ might be attributed to segmentation errors. Indeed, $\mathrm{H}_{\mathrm{CB}}$ estimation might be prone to important instabilities in either fused crown or false detections, affecting the model performance. Overall, this result highlights needs to improve segmentation accuracy as well as the possible drawbacks associated with the use of detailed and computationally demanding crown parameters such as crown-base height. It also confirms the findings of Chen \& al. (2007) and later of Allouis et al. (2013) regarding the interest of $\mathrm{T}_{\mathrm{BV}}$ for estimating volume and biomass. Similarly, bounding volume of trees was found to be a good estimator of various plot-based forest parameters using area-based approaches (André et al., this issue).

At the plot level, our results provided slightly higher errors than those reported by Bouvier et al. (2014) for the same site and with the same data but using an area-based approach (RMSE=12.19\%). As opposed to tree-based approaches, area-based approaches consist in directly assessing plot volume from descriptors computed from the sub-point cloud corresponding to each plot and characterizing the stand as a whole, without identifying trees (Durrieu et al. 2015). The limited improvement obtained using a tree-based approach is probably linked to the relatively low complexity of the forest type under survey. In such forest structures, area-based approaches are known to perform very well using few stand-level LiDAR metrics providing an accurate description of forest stands (Bouvier et al., 2015; Véga et al., 2015). In addition, and as indicated above, the performance of the tree-based approach on this site can be enhanced by improvements in the modeling approach and an optimization of the segmentation algorithm. Despite this issues, tree based approaches remain attractive, because they could provide important information about tree density and stand structure. Also, improvements in segmentation methods can be expected and will lead to improved plot description and volumes estimations, thus providing enhanced information for forest management.

\section{Conclusion}

This paper introduced a method to estimate individual tree volume from airborne LiDAR data in a pinedominated environment. Our results suggested that models using height and either bounding volume or crown volume extracted from point cloud segmentation performed well, but model adjustment was affected by field volume model used to calibrate and validate the models, as well as by local variations in fertility and forestry practices. Scaling the result at the plot level led to a decrease in error by a factor 2 , averaging individual tree over- and under-estimations. High level parameters such as crown base height and crown volume allow to achieve good model quality but might also introduce noise due to imprecision in crown base height estimation. Based on these results, we would recommend to use simple tree descriptors and to introduce parameters accounting for the local tree environment to further refine LiDAR-based volume models. Even if no major improvement in volume assessment accuracy was noted compared to the results obtained over the same site using an areabased approach (Bouvier et al., 2014; Véga et al., 2015) and even if acquisition and processing of high density point clouds remains costly and computer intensive, developing efficient tree-based approaches remains relevant in several ways. For forest inventory purposes, combining area-based and tree-based approaches to assess forest parameters at plot level is likely to improve result accuracy as demonstrated for example by Packalen et al. (2015). For management purposes, having information on tree parameter distributions at stand level is crucial to define appropriate silvicultural work and to plan forest harvesting. In addition, providing information about the tree distribution within a stand over large forest areas could be an asset for the development of sustainable forest management by facilitating establishment and management of irregular and complex stands that are more resistant to climatic and health hazards, host a greater biodiversity and enable a better protection of soils against erosion (Cameron, 2015).

\begin{tabular}{|l|l|l|l|l|l|}
\hline Model & Formula & Adj. ${ }^{2}$ & $\begin{array}{l}\text { RMSE } \\
(\%)\end{array}$ & cv-Adj. ${ }^{2}$ & $\begin{array}{l}\text { cv-RMSE } \\
(\%)\end{array}$ \\
\hline 1 & $0.0003 * \mathrm{H}_{\mathrm{apex}}{ }^{1.9 / 19 *} \mathrm{~T}_{\mathrm{BV}}{ }^{0.344 /}$ & 0.87 & 34.19 & 0.87 & 35.84 \\
\hline 2 & $0.0002{ }^{*} \mathrm{H}_{\mathrm{apex}}{ }^{2.4119 *} \mathrm{C}_{\mathrm{BV}}{ }^{0.2835}$ & 0.88 & 32.80 & 0.88 & 34.68 \\
\hline
\end{tabular}

Table 2 : Tree-level ALS-based model of total above ground volume, with corresponding model performance. R2adj is the adjusted determination coefficient, RMSE the relative root mean squared error, and cv stands for cross-validation. 


\begin{tabular}{|l|l|l|}
\hline Model & $\begin{array}{l}\text { Mean relative } \\
\text { error }(\%)\end{array}$ & RMSE (\%) \\
\hline 1 & 12.52 & 16.19 \\
\hline 2 & 13.62 & 17.87 \\
\hline
\end{tabular}

Table 3 : Mean relative error and RMSE (\%) of the aggregated tree-volume at plot-level
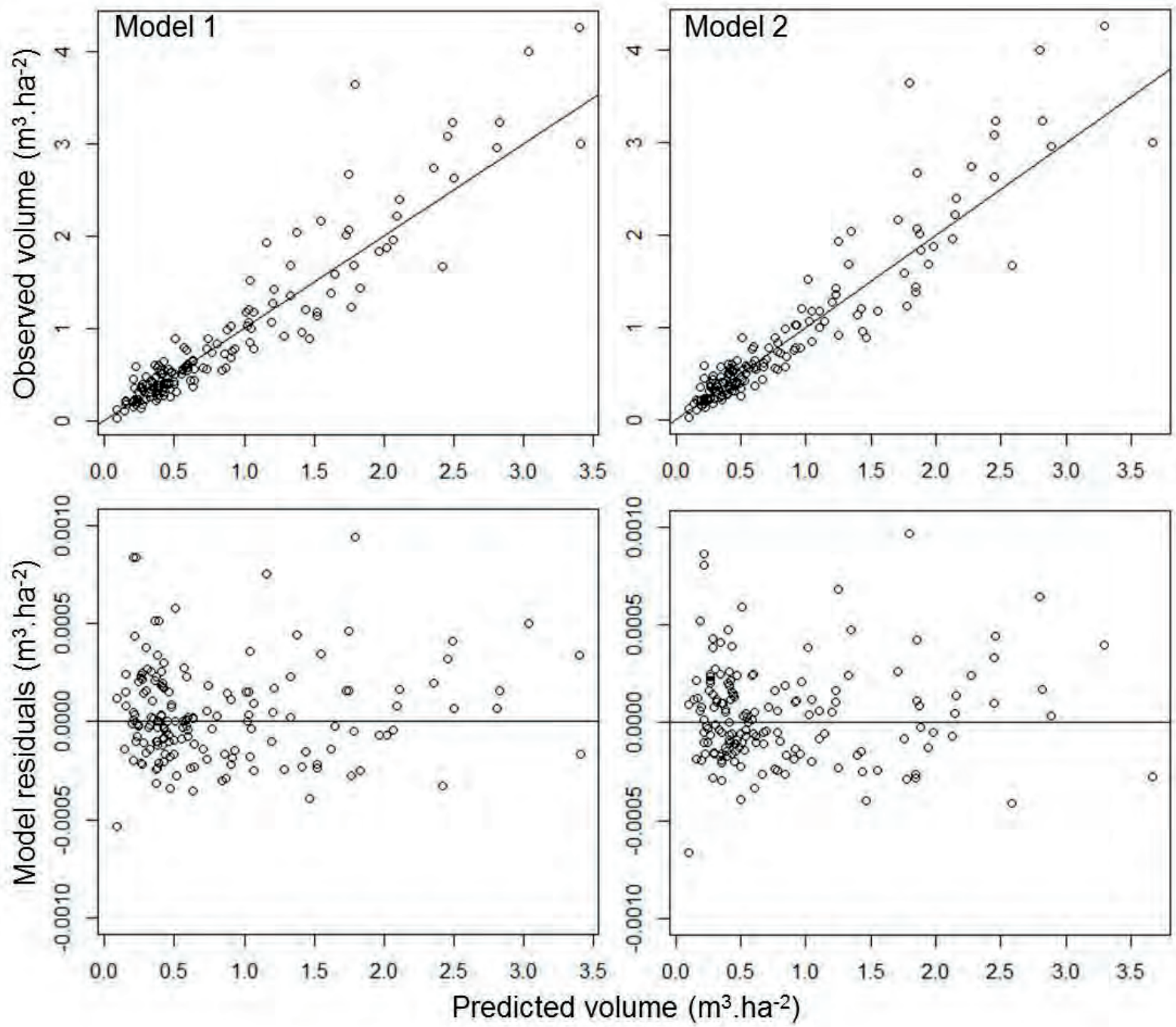

Figure 2 : Predicted versus observed total above ground volume at tree level, and corresponding plot of model residuals 


\section{References}

Allouis T., Durrieu S., Vega C., Couteron P., 2013. Stem volume and above-groundbiomass estimation of individual pine trees from LiDAR data: contribution offull-waveform signals. IEEE Journal of Selected Topics in Applied Earth Observations and Remote Sensing, 6 (2): 924-934.

Antin C., Pélissier R., Vincent G., Couteron P., 2013. Crown allometries are less responsive than stem allometry to tree size and habitat variations in an Indian monsoon forest. Trees, 27(5) : 1485-1495.

Avery T.E., Burkhart H.E., 2001. Forest Measurements, 5th ed. McGraw-Hill, Boston, pp. 456.

Baltsavias E. P., 1999. Airborne laser scanning: basis relations and formulas. ISPRS Journal of Photogrammetry and Remote Sensing, 54 : 199-214.

Bongers F., 2001. Methods to assess tropical rain forest canopy structure: an overview. Plant Ecology, 153: 263-277.

Bouvier, M., Durrieu, S., Fournier, R. A., \& Renaud, J.P., 2015. Generalizing predictive models of forest inventory attributes using an area-based approach with airborne LiDAR data. Remote Sensing of Environment, 156: 322-334.

Bortolot Z. J., Wynne R. H.,2005. Estimating forest biomass using small footprint LiDAR data: An individual tree-based approach that incorporates training data. ISPRS Journal of Photogrammetry and Remote Sensing, 59: 342-360.

Cameron A. D.,2015. Building Resilience into Sitka Spruce (Picea sitchensis (Bong.) Carr.) Forests in Scotland in Response to the Threat of Climate Change. Forests, 6(2): 398-415.

Chen Q., Gong P., Baldocchi D., Tian Y.Q., 2007. Estimating basal area and stem volume for individual trees from LiDAR data. Photogrammetric Engineering \& Remote Sensing, 73(12): 1355-1365.

Deleuze C., Senga Kiessé T., Renaud J.-P., Morneau F., Rivoire M., Santenoise P., Longuetaud F., Mothe F., Hervé J.-C., Bouvet A., 2013. Rapport Final EMERGE Sur Les Modèles de Volumes. Projet ANR08-BIOE-003, Programme BIOE 2008.

Durrieu S., Véga C., Bouvier M., Gosselin F., Renaud J.-P., Saint-André L., 2015. Optical remote sensing of tree and stand heights. In: Thenkabail, S. (Ed), Land Resources Monitoring, Modeling, and Mapping with Remote Sensing. CRC Press (in press).

Evans J.S., Hudak A.T., Faux R., Smith M.S., 2009. Discrete return lidar in natural resources: recommendations for project planning, data processing, and deliverables. Remote Sensing, 1: 776-794.

Ferraz A., Bretar F., Jacquemoud S., Gonçalves G., Pereira L., Tomé M., Soares P., 2012. 3-D mapping of a multi-layered Mediterranean forest using ALS data. Remote Sensing of Environment, 121: 210-223.

Holmgren, J., Persson, Å., 2004. Identifying species of individual trees using airborne laser scanner. Remote Sensing of Environment, 90: 415-423.

Hyyppa J., Kelle O., Lehikoinen M., Inkinen M., 2001. A segmentation-based method to retrieve stem volume estimates from 3-D tree height models produced by laser scanners. IEEE Transactions on Geoscience and Remote Sensing, 39(5): 969-975.
Jung S.-E., Kwak D.-A., Park T., Lee W.-K., Yoo S., 2011. Estimating Crown Variables of Individual Trees Using Airborne and Terrestrial Laser Scanners. Remote Sensing, 3(11): 2346-2363.

Koch B., Heyder U., Weinacker H., 2006. Detection of individual tree crowns in airborne lidar data. Photogrammetric Engineering \& Remote Sensing, 72(4): 357-363.

Korhonen L., Vauhkonen J., Virolainen A., Hovi A., Korpela I., 2013. Estimation of tree crown volume from airborne lidar data using computational geometry. International Journal of Remote Sensing, 34(20): 7236-7248.

Leckie D.G., Gougeon F.A., Tinis S., Nelson T., Burnett C.N., Paradine D., 2005. Automated tree recognition in old growth conifer stands with high resolutiondigital imagery. Remote Sensing of Environment, 94: 311326.

Li W., Guo Q., Jakubowski M.A., Kelly M., 2012. A new method for segmenting individual trees from the lidar point cloud. Photogrammetric Engineering \& Remote Sensing, 78(1): 75-84.

Morsdorf F., Meier E., Kötz B., Itten K.I., Dobbertin M., Allgöwer B., 2004. LIDAR-based geometric reconstruction of boreal type forest stands at single tree level for forest and wildland fire management. Remote Sensing of Environment, 92(3): 353-362.

Næsset E., Gobakken T., Solberg S., Gregoire T.G., Nelson R., Ståhl G., Weydahl D., 2011. Modelassisted regional forest biomass estimation using LiDAR and InSARas auxiliary data: a case study from a boreal forest area. Remote Sensing of Environment, 115(12) : 3599-3614.

Neter J., Wasserman W., Kutner M.H., 1985. Applied linear statistical models, 2nd ed. New York: Irwin.

O'Brien R.M., 2007. A caution regarding rules of thumb for variance inflation factors. Quality \& Quantity, 41: 673-690.

Packalen P., Strunk, J. L., Pitkanen, J., Temesgen, H., \& Maltamo, M. (2015). Edge-Tree Correction for Predicting Forest Inventory Attributes Using AreaBased Approach With Airborne Laser Scanning. IEEE Journal of Selected Topics in Applied Earth Observations and Remote Sensing, 8(3) : 1274-1280.

Peuhkurinen, J., Mehtätalo L., Maltamo M. 2011. Comparing individual tree detection and the area based statistical approach for the retrieval of forest stand characteristics using airborne laser scanning in Scots pine stands. Canadian Journal of Forest Research 41 (3): 583-898.

Picard R.R., Cook R.D., 1984. Cross-validation of regression models. Journal of the American Statistical Association, 79: 575-583.

Popescu S.C., Wynne R.H., Nelson R.F., 2002. Estimating plot-level tree heights withlidar: local filtering with a canopy-height based variable window size. Computers \& Electronics in Agriculture, 37: 7195.

Popescu S.C., Wynne R.H., 2004. Seeing the trees in the forest: using lidar and multi-spectral data fusion with local filtering and variable window size for estimating tree height. Photogrammetric Engineering \& Remote Sensing, 70(5): 589-604 
Popescu S. C., \& Zhao K., 2008. A voxel-based lidar method for estimating crown base height for deciduous and pine trees. Remote Sensing of Environment, 112, 767-781.

Reitberger J., Schnörr C., Krzystek P., Stilla U., 2009. $3 D$ segmentation of singletrees exploiting full waveform LiDAR data. ISPRS Journal of Photogrammetry and Remote Sensing , 64: 561-574

Riaño, D., Meier, E., Allgöwer, B., Chuvieco, E., Ustin, S. L., 2003. Modeling airborne laser scanning data for the spatial generation of critical forest parameters in fire behavior modeling. Remote Sensing of Environment, 86(2) : $177-186$.

van Aardt J. A. N., Wynne R. H., Scrivani J. A., 2008. Lidar-based Mapping of Forest Volume and Biomass by Taxonomic Group Using Structurally Homogenous Segments. Photogrammetric Engineering \& Remote Sensing, 74(8): 1033-1044.
Vega C., Hamrouni A., El Mokhtari S., Morel J., Bock J., Renaud J.-P., Bouvier M., Durrieu S., 2014. PTrees: A Point-Based Approach to Forest Tree Extraction from Lidar Data. International Journal of Applied Earth Observation and Geoinformation, 33: 98-108.

Véga C.; Renaud J.P.; Durrieu S.; Bouvier M., 2015. On the interest of penetration depth, canopy area and volume metrics to improve Lidar-based models of forest parameters. Remote Sensing of Environment, submitted.

Wang Y., Weinacker H., Koch B., 2008. A Lidar point cloud based procedure for vertical canopy structure analysis and $3 D$ single tree modelling in forest. Sensors, 8: 3938-3951.

Wulder M.A., White J.C., Nelson R.F., Næsset E., Ørka H.O., Coops N.C., Hilker T.,Bater C.W., Gobakken T., 2012. Lidar sampling for large-area forest characterization: a review. Remote Sensing of Environment, 121 : 196-209. 